\title{
Synthesis, Characterization and Functionalization of Tetrafunctional Double-Decker Siloxanes
}

\author{
Yujia Liu, ${ }^{\mathrm{a}}$ Nobuhiro Takeda, ${ }^{\mathrm{b}}$ Armelle Ouali, ${ }^{* a, \mathrm{c}}$ and Masafumi Unno*a,b \\ ${ }^{a}$ Gunma University Initiative for Advanced Research (GIAR)-International Open Laboratory with Institute Charles Gerhardt \\ Montpellier (UMR5253 CNRS-UM-ENSCM), Gunma University, Kiryu 376-8515, Japan \\ ${ }^{\mathrm{b}}$ Department of Chemistry and Chemical Biology, Graduate School of Science and Technology, Gunma University, Kiryu \\ 376-8515, Japan \\ ${ }^{\mathrm{c}}$ Institut Charles Gerhardt Montpellier, UMR 5253 CNRS-UM-ENSCM. ENSCM, 8 rue de l'Ecole Normale, 34296 Montpel- \\ lier Cedex 05, France
}

Supporting Information Placeholder

\begin{abstract}
Novel tetravinyl- and tetraallyl-substituted closed double-decker siloxanes (DDSQ) were synthesized, characterized and their structures were elucidated by X-ray crystallographic analysis. Moreover, it was shown that peripheral olefins could successfully undergo hydrosilylation quantitatively. Such tetra-functionalizable DDSQ (DDSQ-Vinyl 4 and DDSQ-Allyl 4 ) thus constitute promising building blocks for more complex inorganic-organic hybrid materials.
\end{abstract}



by hydrosilylation for the former ones ${ }^{12}$ or through catalytic metathesis, silylation or Heck couplings for the latter ones. ${ }^{13}$

Scheme 1. Structures and synthetic pathways of double-decker siloxanes (DDSQ) derivatives. istry. Among them, polyhedral oligomeric silsesquioxanes (POSS), and especially cubic octasilsesquioxanes $\left(\mathrm{T}_{8}\right)$, involving inorganic nano-sized $\mathrm{Si}-\mathrm{O}$ core and organic reactive peripheral parts, have been intensively studied and constitute a tunable platform for many applications. ${ }^{2}$ Just over a decade ago, another class of POSS, the double-decker siloxanes (DDSQ), was reported by Yoshida et al. for the first time. ${ }^{3}$ The current chemistry and applications of DDSQ have been recently reviewed by Marciniec et $a l .{ }^{4}$ Two possible structures may be distinguished: the first one is an open $\mathrm{T}_{8} \mathrm{M}_{4}$ (DDSQ-4OSi) architecture ${ }^{5}$ (Scheme 1a) while the other one is a closed $\mathrm{D}_{2} \mathrm{~T}_{8}$ (DDSQ-2OSi) framework (1b). ${ }^{3 \mathrm{~b}, 6}$ Both of them are prepared from the same DDSQ-4OX (X = H or Na) precursor by nucleophilic substitution with the suitable functional chlorosilane or dichlorosilane respectively (Scheme 1a,b). ${ }^{4,7} \mathrm{~T}_{8} \mathrm{M}_{4}$ and $\mathrm{T}_{8} \mathrm{D}_{2}$-DDSQ structures were applied in various areas of chemistry such as optics, ${ }^{8}$ coordination chemistry ${ }^{9}$ or polymer nanocomposites. ${ }^{10-14}$

In general, the introduction of reactive groups onto the $\mathrm{T}_{8} \mathrm{M}_{4}$ and $\mathrm{T}_{8} \mathrm{D}_{2}$-DDSQ architectures is highly relevant to next include the DDSQ units in more complex systems (e.g. electronic or optic devices, coordination complexes, hybrid polymers,...). Along these lines, $\mathrm{T}_{8} \mathrm{M}_{4}$-DDSQ involving four $\mathrm{H}$, alkenyl or ethynyl functional groups were recently designed. ${ }^{15}$ Besides, the number of examples of difunctional closed $\mathrm{T}_{8} \mathrm{D}_{2}$-DDSQ architectures with one reactive group on each side has also increased (e. g. $\mathrm{FG}=p-\mathrm{C}_{6} \mathrm{H}_{4}-\mathrm{NH}_{2},{ }^{11} \mathrm{H},{ }^{12}$ alkenyl, ${ }^{13}-\left(\mathrm{CH}_{2}\right)_{3}-\mathrm{N}_{3},{ }^{14}-\left(\mathrm{CH}_{2}\right)_{3}{ }^{-}$ $\mathrm{Cl},{ }^{16}$ Scheme $\left.1 \mathrm{~b}\right)$. Difunctional $\mathrm{T}_{8} \mathrm{D}_{2}$-DDSQ are generally obtained as isomers mixtures, geometric cis and trans- isomer formation corresponding to the different spatial arrangements of the FG and R groups on the DDSQ core (Scheme 1b). ${ }^{11,13,14}$ DDSQ involving two Si-H or two alkenyl groups (Scheme 1b, $\mathrm{T}_{8} \mathrm{D}_{2}, \mathrm{FG}=\mathrm{H}$ or $\mathrm{CH}=\mathrm{CH}_{2}$ resp.) can be further functionalized

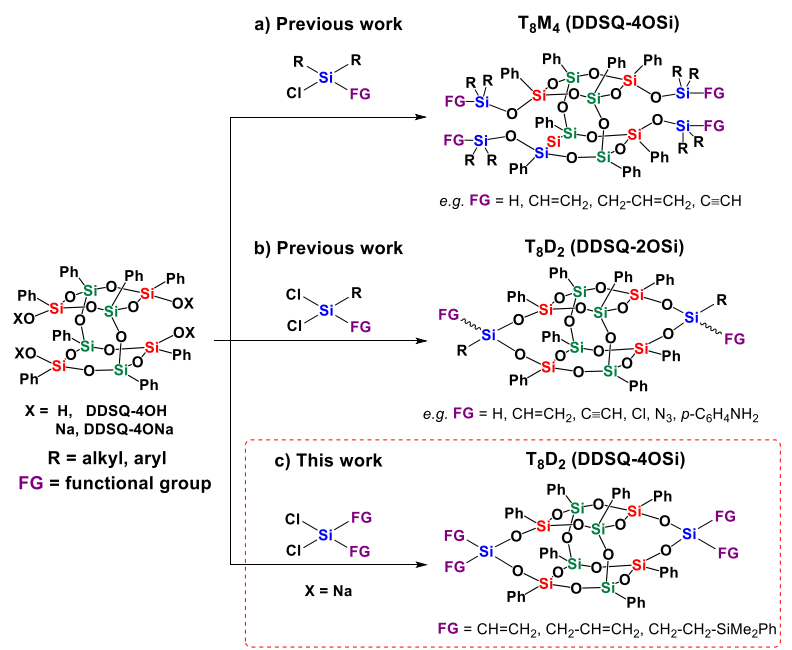

Although examples of tetrafunctional $\mathrm{T}_{8} \mathrm{M}_{4}$-DDSQ have already been reported, ${ }^{15}$ the development of synthetic methodologies leading to other multivalent functionalizable DDSQ architectures is highly desirable. Along these lines, closed $\mathrm{T}_{8} \mathrm{D}_{2}$ architectures displaying four reactive groups have been hardly explored so far (Scheme 1c). Different properties are yet expected from these closed and more rigid DDSQ structures compared to related open tetrafunctional $\mathrm{T}_{8} \mathrm{M}_{4}$-DDSQ previously described. ${ }^{15}$ Herein, the synthesis of novel tetravinyl- and tetraallyl-substituted closed $\mathrm{T}_{8} \mathrm{D}_{2}$-DDSQ (Scheme 2, DDSQ$\mathrm{Vinyl}_{4}(\mathbf{1})$ and DDSQ-Allyl 4 (2)) is reported. DDSQ 1 and 2 were characterized by several techniques including multinuclear NMR and mass spectroscopies, and their structures were elucidated by X-ray crystallography. Moreover, peripheral 
alkenyl groups could be further successfully functionalized through hydrosilylation with $\mathrm{Me}_{2} \mathrm{PhSiH}$ as model substrate, showing that reported tetra-functionalizable $\mathrm{T}_{8} \mathrm{D}_{2}$-DDSQ are promising precursors for inorganic-organic hybrid materials.

\section{RESULTS AND DISCUSSION}

DDSQ 1 and $\mathbf{2}$ were synthesized by the hydrolytic condensation of incompletely condensed silsesquioxane DDSQ-4ONa $\left(\mathrm{Ph}_{8} \mathrm{Si}_{8} \mathrm{O}_{8}\right)(\mathrm{ONa})_{4}{ }^{17}$ with commercially available divinyldichlorosilane and diallyldichlorosilane respectively in toluene (Scheme 2). The target tetra-substituted DDSQ 1 and $\mathbf{2}$ were obtained in $67 \%$ and $50 \%$ isolated yield respectively after washing of the crude products with 2-propanol. These isolated yields are higher than those generally obtained for difunctional $T_{8} \mathrm{D}_{2}$ DDSQ (Scheme 1b), only one isomer being formed due to the symmetry of the dichlorosilane used (Scheme 1c). Noteworthy, DDSQ-4OH, obtained from DDSQ-4ONa under acidic conditions, ${ }^{17}$ is often used as the precursor for the preparation of $\mathrm{T}_{8} \mathrm{D}_{2}$-DDSQ. The synthetic pathway proposed here allows not only to skip the hydrolysis step, but also to avoid the formation of $\mathrm{HCl}$ gas during the condensation. The presence of triethylamine was however required for obtaining better yields and selectivities, although its role can not be rationalized yet.

Scheme 2: Synthesis of DDSQ 1 and 2 from DDSQ-4ONa.

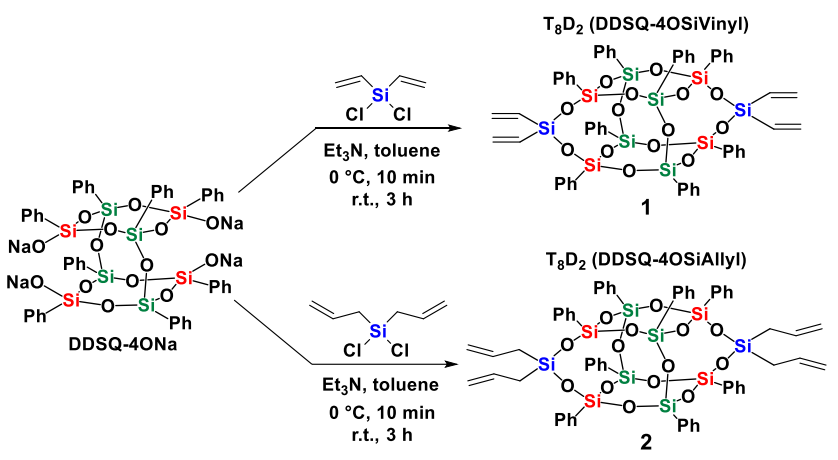

Crystals were next grown and the structures of $\mathbf{1}$ and $\mathbf{2}$ could be studied by X-ray crystallography (Figures 1 and 2). As expected, both symmetrical structures were very similar. The SiO bond lengths were in the ranges of 1.605(6)-1.636(7) $\AA$ (average 1.617(6) $\AA$ ) for 1 and 1.607(9)-1.634(8) $\AA$ (average 1.619(9) А) for 2 which was in accordance with previously reported $\mathrm{T}_{8} \mathrm{D}_{2}$-DDSQ including symmetrical tetraphenyl- ${ }^{7}$ or unsymmetrical divinyl- ${ }^{13 \mathrm{~d}}$ DDSQ. $\mathrm{Si}-\mathrm{C}$ lengths were also consistent with those found in the same previous reports (in the ranges of 1.839(2)-1.847(7) $\AA$ (average 1.842(5) $\AA$ ) for 1 and

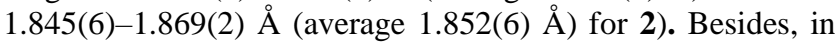
compound 1 , the $\mathrm{Si}-\mathrm{O}-\mathrm{Si}$ bond angles vary from $137.2(2)$ to $161.0(8)^{\circ}$ and in compound 2 , the $\mathrm{Si}-\mathrm{O}-\mathrm{Si}$ bond angles are in the range of $138.8(8)-166.3(7)^{\circ}$. The $\mathrm{Si}-\mathrm{O}-\mathrm{Si}$ bond angles in two compounds display a considerable variation due to the presence of both 8 - and 10-membered rings. Such phenomenon was also observed previously for tetraphenyl- ${ }^{7}$ or divinyl- ${ }^{13 \mathrm{~d}}$ DDSQ.

DDSQ 1 and 2 were analyzed by matrix-assisted laser desorption/ionization coupled time-of-flight (MALDI-TOF) mass spectroscopy and the experimental mass spectra were in very good agreement with the calculated molecular weight (see SI, Figure S8). ${ }^{1} \mathrm{H},{ }^{13} \mathrm{C}$ and ${ }^{29} \mathrm{Si} \mathrm{NMR}$ spectroscopies were also performed to characterize DDSQ 1 and 2. Both ${ }^{29} \mathrm{Si} \mathrm{NMR} \mathrm{spectra}$ clearly displayed signals corresponding to the D-group silicon atoms (Si in blue, Scheme 2), Si atoms bonded to two oxygen atoms, at $\delta-46.7$ in $\mathbf{1}$ and -28.5 in 2 . $^{11 \mathrm{~b}}$ The shielding observed in the case of 2 might be rationalized by the enhanced electrodonating properties of the allyl substituents compared to the vinyl ones. Besides, the ${ }^{29} \mathrm{Si}$ resonances at $\delta-78.2$ and $-78.8 \mathrm{ppm}$, respectively for $\mathbf{1}$ and $\mathbf{2}$, have been assigned to T-group silicon atoms from the core, nearest to the $\mathrm{D}$-group silicon atoms ( $\mathrm{Si}$ in red connected to three oxygen atoms). ${ }^{11 \mathrm{~b}}$ The other internal Tgroup silicon atoms ( $\mathrm{Si}$ in green) gave rise to singlets at $\delta-79.5$ and $\delta-79.6 \mathrm{ppm}$ (for $\mathbf{1}$ and $\mathbf{2}$ respectively). In conclusion, these spectroscopic data, confirmed by ${ }^{1} \mathrm{H}$ and ${ }^{13} \mathrm{C}$ NMR spectra (ESI, S2-S4), are consistent with the successful synthesis of $\mathbf{1}$ and $\mathbf{2}$.

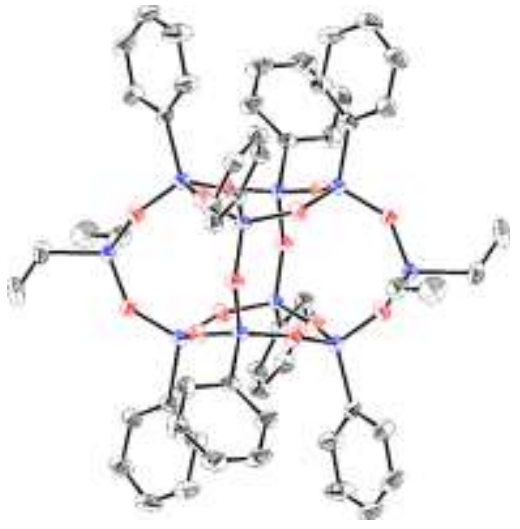

Figure 1. Crystal structure of 1. Black: carbon; blue: silicon; red: oxygen. Thermal ellipsoids are shown at the $50 \%$ probability level. All hydrogen atoms are omitted for clarity.

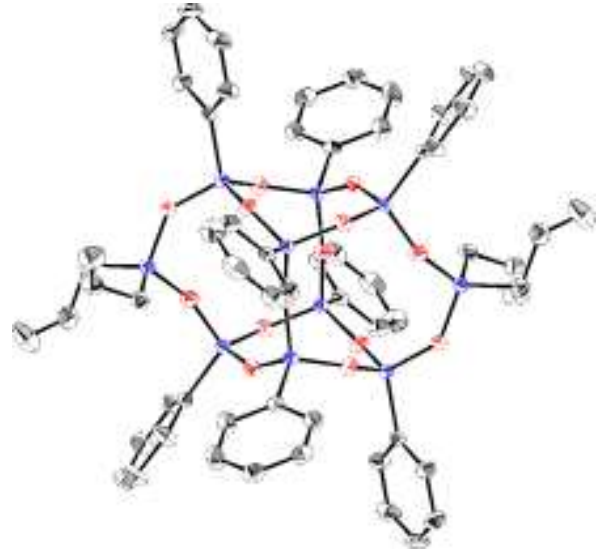

Figure 2. Crystal structure of 2. Black: carbon; blue: silicon; red: oxygen. Thermal ellipsoids are shown at the $50 \%$ probability level. All hydrogen atoms are omitted for clarity.

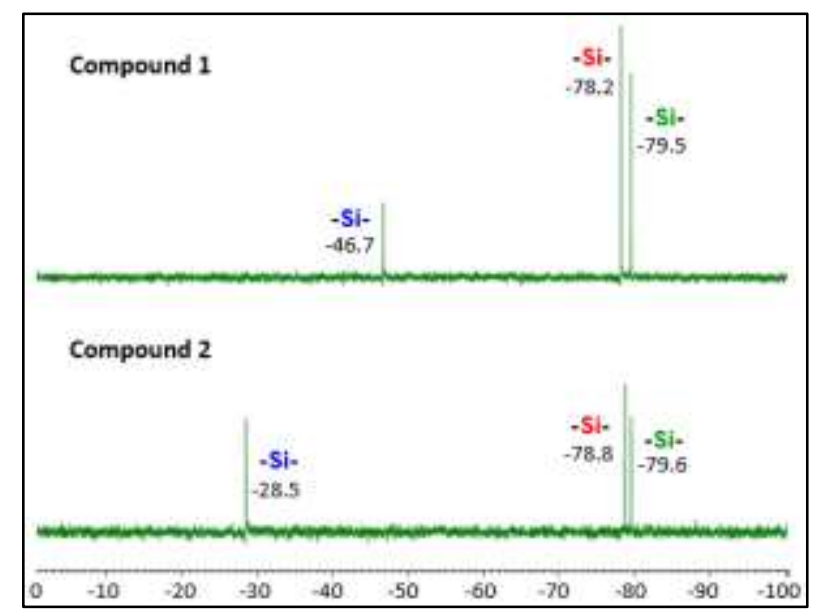

Figure 3. ${ }^{29} \mathrm{Si} \mathrm{NMR} \mathrm{spectra}\left(\mathrm{CDCl}_{3}\right)$ for the DDSQ 1 and 2. Chemical shifts are in ppm unit. 
With the new functionalizable $\mathrm{T}_{8} \mathrm{D}_{2}$-DDSQ 1 and $\mathbf{2}$ in hand, the reactivity of external alkenyl (vinyl and allyl) groups was next explored. Catalytic hydrosilylation was thus performed by using dimethylphenylsilane as a model substrate (Scheme 3) in the presence of the Karstedt's catalyst. Expected $\mathrm{T}_{8} \mathrm{D}_{2}$-DDSQ 3 and $\mathbf{4}$, respectively obtained from $\mathbf{1}$ and $\mathbf{2}$, were obtained in 70 and $77 \%$ isolated yields respectively, after recrystallization of the crude product from a chloroform/2-propanol mixture. Crystals were next grown and the structures of $\mathbf{3}$ and $\mathbf{4}$ could be studied by X-ray crystallography (Figures 4,5 ). The $\mathrm{Si}-\mathrm{O}$ bond lengths were found to be quite similar to those observed for $\mathbf{1}$ and 2 (in the range of 1.597(5)-1.634(7) $\AA$ (average 1.617(6) $\AA$ ) for 3 and in the range of $1.608(2)-1.624(2)$ (average $1.616(8) \AA$ ) for 4). The $\mathrm{Si}-\mathrm{O}-\mathrm{Si}$ bond angles vary from $135.2(0)$ to $173.8(2)^{\circ}$ in 3 and from $147.2(5)$ to $156.2(8)^{\circ}$ in $\mathbf{4}$. This large deviation of bond angels clearly indicates the flexible structure of the framework. ${ }^{29} \mathrm{Si}$ NMR spectra of 3 and 4 displayed expected and previously described signals for $\mathrm{T}$ silicon atoms (red and green ones) corresponding to the DDSQ core (see SI). For 3 , the signals of D silicon atoms (blue color) were shifted to $\delta$ 21.4 as compared to $\delta-46.7$ in $\mathbf{1}$ which is in the favor of a successful reduction of the vinyl function. Noteworthy, the appearance of a new singlet at $\delta-0.9$ and $\delta-3.5$ ppm for 3 and 4 respectively, is consistent with the formation of the carbosilane moiety ${ }^{18}$ and therefore the successful and quantitative hydrosilylation of vinyl and allyl units. Data obtained from ${ }^{1} \mathrm{H}$ and ${ }^{13} \mathrm{C}$ NMR and MALDI-TOF spectroscopies confirmed the structures of $\mathbf{3}$ and $\mathbf{4}$ (see SI, Figures S5-S6, S9). To our knowledge, the only previous example of tetrafunctionalizable DDSQ involves four reactive $\mathrm{Si}-\mathrm{Cl}$ bonds ${ }^{3 \mathrm{~b}}$ likely to react with hydroxylated compounds. The non-hydrolizable unsaturated C-C bonds reported here open the way to many possibilities in terms of functionalizations beyond hydrosilylation such as other hydroelementations (hydroaminations, hydroborations...), metathesis or Heck couplings.

Scheme 3: Hydrosilylation of DDSQ 1 and 2.

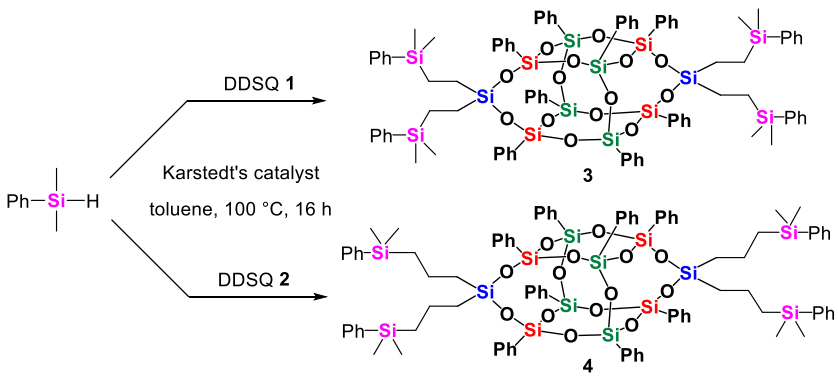

Noteworthy, for all $\mathrm{T}_{8} \mathrm{D}_{2}$-DDSQ 1 to $\mathbf{4}$, the results of thermogravimetric (TG) analysis in $\mathrm{N}_{2}$ show high $\mathrm{Td}_{5}\left(388{ }^{\circ} \mathrm{C}\right.$ for 1, $452{ }^{\circ} \mathrm{C}$ for $2,440{ }^{\circ} \mathrm{C}$ for 3 and $446{ }^{\circ} \mathrm{C}$ for 4 , see SI, Figures S14-S16) demonstrating their high thermal stability. As a point of comparison, the related non-functionalizable $\mathrm{T}_{8} \mathrm{D}_{2}$-DDSQ bearing 4 phenyl groups was previously reported to display a $\mathrm{Td}_{5}$ of $425{ }^{\circ} \mathrm{C}$ which is in the same order of magnitude. ${ }^{7}$ The melting point (Tm) of compounds 1-4 decreased following the order of the side siloxane chain length.

In summary, novel $\mathrm{T}_{8} \mathrm{D}_{2}$-DDSQ involving four reactive substituents, either vinyl- or allyl-, were prepared, characterized and their structures were elucidated by X-ray crystallographic analysis. The synthetic method is simple and the expected $T_{8} \mathrm{D}_{2-}$ DDSQ 1 and $\mathbf{2}$ could be isolated in good yields and very high purities. In addition, terminal alkenyl substituents were shown to successfully undergo hydrosilylation with dimethylphenylsilane used as a model substrate. DDSQ 1 and $\mathbf{2}$ thus constitute promising building blocks for inorganic-organic hybrid materials and applications are currently studied in our laboratories.

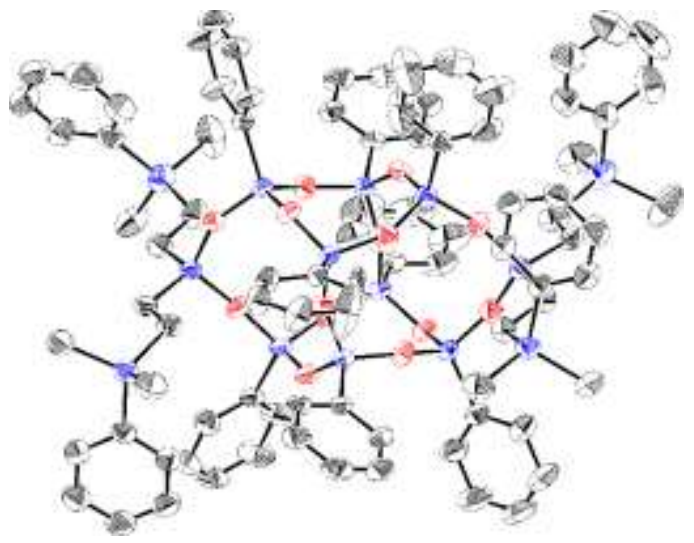

Figure 4. Crystal structure of 3. Black: carbon; blue: silicon; red: oxygen. Thermal ellipsoids are shown at the $50 \%$ probability level. All hydrogen atoms are omitted for clarity.

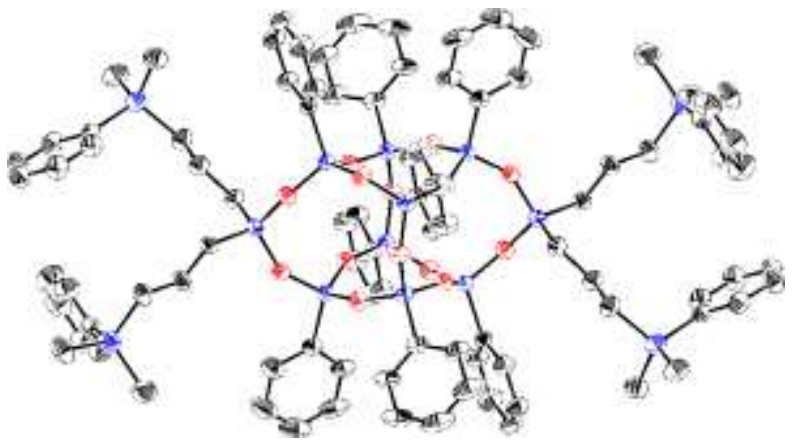

Figure 5. Crystal structure of 4. Black: carbon; blue: silicon; red: oxygen. Thermal ellipsoids are shown at the $50 \%$ probability level. All hydrogen atoms are omitted for clarity.

\section{EXPERIMENTAL SECTION}

THF was dried using mBRAUN purification system. Toluene was distilled from calcium hydride, stored on $4 \AA$ activated molecular sieves under an argon atmosphere. Triethylamine was distilled from potassium hydroxide, stored on potassium hydroxide under an argon atmosphere with protection from light. Divinyldichlorosilane and diallyldichlorosilane were purchased from ShinEtsu Chemical Co., Ltd and used without further purification. All reactions were performed under argon atmosphere. The Fourier transformation nuclear magnetic resonance (NMR) spectra were obtained using a JEOL JNM-ECS $300\left({ }^{1} \mathrm{H}\right.$ at $300.53 \mathrm{MHz},{ }^{13} \mathrm{C}$ at $75.57 \mathrm{MHz},{ }^{29} \mathrm{Si}$ at $\left.59.71 \mathrm{MHz}\right)$, JEOL JNM-ECA $400\left({ }^{1} \mathrm{H}\right.$ at $399.78 \mathrm{MHz})$ and JEOL JNM-ECA $600\left({ }^{1} \mathrm{H}\right.$ at $600.17 \mathrm{MHz},{ }^{13} \mathrm{C}$ at $150.91 \mathrm{MHz},{ }^{29} \mathrm{Si}$ at $119.24 \mathrm{MHz}$ ) NMR instruments. For ${ }^{1} \mathrm{H}$ NMR, chemical shifts are reported as units (ppm) relative to $\mathrm{SiMe}_{4}$ (TMS) and the residual solvents peaks were used as standards. For ${ }^{13} \mathrm{C}$ NMR and ${ }^{29} \mathrm{Si}$ NMR, chemical shifts are reported as units (ppm) relative to $\mathrm{SiMe}_{4}$ (TMS), the residual solvents peaks were used as standards and spectra were obtained with complete proton decoupling. MALDI-TOF mass analysis were carried out with a Shimadzu AXIMA Performance instrument using 2,5-dihydroxybenzoic acid (dithranol) as the matrix and $\mathrm{AgNO}_{3}$ as the ion source. All reagents used were of analytical grade. Elemental analyses were performed by the Center for Material Research by Instrumental Analysis (CIA), Gunma University, Japan. Infrared spectra were 
measured with a Shimadzu FTIR-8400S. The thermogravimetric analyses were carried out with a Rigaku thermal gravimetric analyzer (Thermoplus TG-8120). The investigations were carried out under nitrogen flow $\left(250 \mathrm{~mL} \mathrm{~min}^{-1}\right)$ with a heating rate $10{ }^{\circ} \mathrm{C} \mathrm{min}$ ${ }^{1}$. All samples were measured with temperatures ranging from 50 ${ }^{\circ} \mathrm{C}$ to $1000{ }^{\circ} \mathrm{C}$, where they remained for 5 minutes. Weight loss and heating rate were continuously recorded along the experiment.

Synthesis of 1. Divinyldichlorosilane $(0.85 \mathrm{~mL}, 6.0 \mathrm{mmol})$ was added dropwise to a mixture of DDSQ-4ONa (2.314 g, $2.0 \mathrm{mmol})$ and triethylamine $(0.81 \mathrm{~mL}, 6.0 \mathrm{mmol})$ in toluene $(23.5 \mathrm{~mL})$ at 0 ${ }^{\circ} \mathrm{C}$. The mixture was then allowed to stir at room temperature for 3 $\mathrm{h}$. Chloroform was added to the reaction mixture, and the organic layer was washed with saturated ammonium chloride aqueous solution and brine. The organic phase was dried over anhydrous sodium sulfate and evaporated to afford a crude solid further purified by washing with 2-propanol to give $1(1.64 \mathrm{~g}, 67 \%)$ as colorless crystals. Spectral data for 1: ${ }^{1} \mathrm{H}$ NMR $\left(600.17 \mathrm{MHz}, \mathrm{CDCl}_{3}\right): \delta$ 5.99-6.16 (m, 12H), 7.19-7.22 (m, 8H), 7.27-7.28 (m, 8H), 7.41$7.46(\mathrm{~m}, 16 \mathrm{H}), 7.57-7.58(\mathrm{~m}, 8 \mathrm{H}) \mathrm{ppm} .{ }^{13} \mathrm{C}\left\{{ }^{1} \mathrm{H}\right\}$ NMR $(150.91$ $\left.\mathrm{MHz} \mathrm{CDCl}_{3}\right): \delta 127.76,127.97,130.49,130.57,131.09,131.93$, 133.62, 134.17, 134.28, $136.00 \mathrm{ppm} .{ }^{29} \mathrm{Si}\left\{{ }^{1} \mathrm{H}\right\}$ NMR $(119.24 \mathrm{MHz}$, $\left.\mathrm{CDCl}_{3}\right): \delta-46.68,-78.21,-79.54 \mathrm{ppm}$. MALDI-TOF MS $(\mathrm{m} / \mathrm{z})$ : $1252.31\left([\mathrm{M}+\mathrm{Na}]^{+}\right.$, calcd 1252.86).

Synthesis of 2. Same procedure as for the synthesis of 1 from diallyldichlorosilane $(1.0 \mathrm{~mL}, 6.0 \mathrm{mmol})$. The crude product was further purified by washing with 2-propanol to give 2 (1.298 g, 50 $\%)$ as a colorless crystal. Spectral data for 2: ${ }^{1} \mathrm{H}$ NMR (600.17 $\left.\mathrm{MHz}, \mathrm{CDCl}_{3}\right): \delta 1.79-1.83(\mathrm{~m}, 8 \mathrm{H}), 4.77-4.92(\mathrm{~m}, 8 \mathrm{H}), 5.77-5.84$ (m, 4H), 7.21-7.57 (m, $40 \mathrm{H}) \mathrm{ppm} .{ }^{13} \mathrm{C}\left\{{ }^{1} \mathrm{H}\right\} \mathrm{NMR}(150.91 \mathrm{MHz}$, $\left.\mathrm{CDCl}_{3}\right): \delta 22.79,127.83,127.94,130.59,131.05,131.85,132.40$, 134.19 ppm. ${ }^{29} \mathrm{Si}\left\{{ }^{1} \mathrm{H}\right\}$ NMR (119.24 MHz, $\left.\mathrm{CDCl}_{3}\right): \delta-28.49$, 78.75, $-79.58 \mathrm{ppm}$. MALDI-TOF MS $(\mathrm{m} / \mathrm{z}): 1308.31\left([\mathrm{M}+\mathrm{Na}]^{+}\right.$, calcd 1308.97).

Synthesis of 3. To a mixture of $\mathbf{1}(123 \mathrm{mg}, 0.1 \mathrm{mmol})$ and dimethylphenylsilane $(92 \mathrm{uL}, 0.6 \mathrm{mmol})$ in toluene $(0.6 \mathrm{~mL})$, Karstedt catalyst ( $2 \% \mathrm{Pt}$, commercial bottle, diluted 100 times in distilled toluene under argon, $112 \mu \mathrm{L}, 0.0025 \mathrm{mmol}$ ) was added at room temperature. When the addition was finished, the mixture was allowed to stir for 10 minutes at room temperature and then heated to $100{ }^{\circ} \mathrm{C}$ for 16 hours. The reaction mixture was passed through a silica plug and the filtrate evaporated to dryness to afford a slightly yellowish solid further purified by recrystallization from chloroform and 2-propanol to give $3(0.124 \mathrm{~g}, 70 \%)$ as a colorless crystal. Spectral data for 3: ${ }^{1} \mathrm{H}$ NMR $\left(600.17 \mathrm{MHz}, \mathrm{CDCl}_{3}\right): \delta 0.10(\mathrm{~s}, 24 \mathrm{H})$, 0.54-0.57 (m, 8H), 0.79-0.82 (m, 8H), 7.12-7.14 (m, 8H), 7.19-7.35 (m, 32H), 7.38-7.43 (m, 12H), $7.50(\mathrm{dd}, J=9.28,1.37 \mathrm{~Hz}, 8 \mathrm{H})$ ppm. ${ }^{13} \mathrm{C}\left\{{ }^{1} \mathrm{H}\right\}$ NMR $\left(150.91 \mathrm{MHz}, \mathrm{CDCl}_{3}\right): \delta-3.53,6.36,7.35$, 127.81 (overlapped), 127.95, 128.81, 130.44, 130.46, 131.25, 132.34, 133.74, 134.12, 134.19, 139.23 ppm. ${ }^{29} \mathrm{Si}\left\{{ }^{1} \mathrm{H}\right\} \mathrm{NMR}$ (119.24 MHz, $\left.\mathrm{CDCl}_{3}\right): \delta-0.93,-21.37,-78.21,-79.17 \mathrm{ppm}$. MALDI-TOF MS (m/z): 1797.59 ([M+Na $]^{+}$, calcd 1797.93).

Synthesis of 4. Same procedure as for the synthesis of $\mathbf{3}$ from $\mathbf{2}$ (129 $\mathrm{mg}, 0.1 \mathrm{mmol}$ ). The crude product was further purified by recrystallization from chloroform and 2-propanol to give $4(0.141 \mathrm{~g}$, $77 \%)$ as a colorless crystal. Spectral data for $4:{ }^{1} \mathrm{H}$ NMR $(600.17$ $\left.\mathrm{MHz} \mathrm{CDCl}_{3}\right): \delta 0.05$ (s, $\left.2 \mathrm{H}\right), 0.72-0.81(\mathrm{~m}, 16 \mathrm{H}), 1.42-1.48(\mathrm{~m}$, $8 \mathrm{H}), 7.15-7.18(\mathrm{~m}, 8 \mathrm{H}), 7.22-7.30(\mathrm{~m}, 20 \mathrm{H}), 7.33-7.45(\mathrm{~m}, 24 \mathrm{H})$, 7.51-7.52 (m, 8H) ppm. ${ }^{13} \mathrm{C}\left\{{ }^{1} \mathrm{H}\right\} \mathrm{NMR}\left(150.91 \mathrm{MHz}, \mathrm{CDCl}_{3}\right): \delta-$ $3.05,17.54,19.89,20.21,127.78,127.81,127.94,128.78,130.43$, $130.47,131.28,132.32,133.62,134.10,134.25,139.82 \mathrm{ppm}$. ${ }^{29} \mathrm{Si}\left\{{ }^{1} \mathrm{H}\right\}$ NMR $\left(119.24 \mathrm{MHz}, \mathrm{CDCl}_{3}\right): \delta 3.45,-18.95,-78.34$, $79.17 \mathrm{ppm}$. MALDI-TOF MS $(\mathrm{m} / \mathrm{z}): 1853.70\left([\mathrm{M}+\mathrm{Na}]^{+}\right.$, calcd 1854.04).
C rystallography.

For crystal data, data collection and refinement, see supporting information (S10-S11). CCDC 1880537 (1), CCDC 1880536 (2), CCDC 1880538 (3) and CCDC 1887329 (4) contain the supplementary crystallographic data for this paper. These data can be obtained free of charge from the Cambridge Crystallographic data Centre via www.ccdc.cam.ac.uk/data_request/cif. $\square$

\section{ASSOCIATED CONTENT}

\section{Supporting Information}

${ }^{1} \mathrm{H},{ }^{13} \mathrm{C},{ }^{29} \mathrm{Si}$ NMR spectra, MALDI-TOF-MS spectra, IR spectra, crystallographic data and TGA for 1, 2, 3 and 4. The Supporting Information is available free of charge on the ACS Publications website.

\section{AUTHOR INFORMATION}

\author{
Corresponding Author \\ * E-mail: unno@gunma-u.ac.jp; armelle.ouali@enscm.fr.
}

\section{REFERENCES}

(Word Style "TF_References_Section"). References are placed at the end of the manuscript. Authors are responsible for the accuracy and completeness of all references. Examples of the recommended formats for the various reference types can be found at http://pubs.acs.org/page/4authors/index.html. Detailed information on reference style can be found in The ACS Style Guide, available from Oxford Press.

(1) The term silsesquioxanes refers to structures with the empirical formula $\mathrm{RSiO}_{3 / 2}(\mathrm{R}=\mathrm{H}$, alkyl or aryl). Baney, R. H.; Itoh, M.; Sakakibara, A.; Suzuki, T. Silsesquioxanes. Chem. Rev. 1995, 95, 1409-1430.

(2) (a) Laine, R. M.; Roll, M. F. Polyhedral Silsesquioxanes. Macromolecules 2011, 44, 1073-1109; (b) Cordes, D. B.; Lickiss, P. D.; Rataboul, F. Recent Developments in the Chemstry of Cubic Polyhedral Oligosilsesquioxanes. Chem. Rev. 2010, 110, 2081-2173; (c) Cordes, D. B.; Lickiss, P. D. in Applications of Polyhedral Oligomeric Silsesquioxanes, Advances in Silicon Science 3, ed. Hartmann-Thompson, C. Springer, 2011. (d) Liu, H.; Kondo, S.-I.; Takeda, N.; Unno, M. Synthesis of octacarboxy Spherosilicate. J. Am. Chem. Soc. 2008, 130, 10074-10075.

(3) (a) Morimoto, Y.; Watanabe, K.; Ootake, N.; Inagaki, J.; Yoshida, K.; Ohguma, K. Silsesquioxane derivatives and process for production thereof. US 7169873 (B2), 2007; (b) Morimoto, Y.; Watanabe, K.; Ootake, N.; Inagaki, J.; Yoshida, K.; Ohguma, K. Silsesquioxane derivatives and process for production thereof. WO 03/024870 (A1), 2003; (c) Yoshida, K. Polymer Preprints Japan, 2003, 52, 316; (d) Ootake, N.; Yoshida, K.; Organic silicon compound and method for producing same, and polysiloxane and method for producing same. US Pat. Appl. 2006/0155091(A1), 2006.

(4) Dudziec, B.; Marciniec, B. Double-Decker Silsesquioxanes: Current Chemistry and Applications. Current Org. Chem. 2017, 21, 27942813.

(5) (a) Yoshizawa, K.; Morimoto, Y.; Watanabe, K.; Ootake, N. Silsesquioxane Derivatives and Production Process. US 7319129 (B2), 2008; (b) Oikawa, H.; Yamahiro, M.; Yoshida, K.; Ootake, N.; Watanabe, K.; Ohno, K.; Tsujii, Y.; Fukuda, T. Silicon compound. US 7256243 (B2), 2007.

(6) Oikawa, H.; Yamahiro, M.; Ohguma, K.; Ootake, N.; Watanabe, K.; Ohno, K.; Tsujii, Y.; Fukuda, T. Organosilicon compound. US 7375170 (B2), 2008.

(7) Endo, H.; Takeda, N.; Unno, M. Synthesis and Properties of Phenylsilsesquioxanes with Ladder and Double-Decker Structures. Organometallics 2014, 33, 4148-4151.

(8) Kohri, M.; Matsui, J.; Watanabe, A.; Miyashita, T. Synthesis and Optoelectronic Properties of Completely Carbazole-substituted Double-decker-shaped Silsesquioxane. Chem. Lett. 2010, 39, 1162-1163. 
(9) (a) Espinas, J.; Pelletier; Abou-Hamad, E.; Emsley, L.; Basset, J.M. A Silica-Supported Double-Decker Silsesquioxane Provides a Second Skin for the Selective Generation of Bipodal Surface Organometallic Complexes. Organometallics 2012, 31, 7610-7617; (b) Hay, M. T., Seurer, B.; Holmes, D.; Lee, A. A Novel Linear Titanium(IV)POSS Coordination Polymer. Macromolecules 2010, 43, 2108-2110.

(10) (a) Kucuk, A. C., Matsui, J.; Miyashita, T. Effects of Subphase Composition on the Monolayer Behavior of "core-coronae" type Hybrid Amphiphiles. Thin Solid Films 2013, 534, 577-583; (b) Kucuk, A. C., Matsui, J.; Miyashita, T. Proton-Conducting Electrolyte Film of Double-Decker-Shaped Polyhedral Silsesquioxane Containing Covalently Bonded Phosphonic Acid Groups. J. Mater. Chem. 2012, 22, 3853-3858; (c) Kucuk, A. C., Matsui, J.; Miyashita, T. Effects of Hydrogen Bonding on the Monolayer Properties of Amphiphilic DoubleDecker-Shaped Polyhedral Silsesquioxanes. Langmuir 2011, 27, 63816388. (d) Kucuk, A. C., Matsui, J.; Miyashita, T. Langmuir-Blodgett Films Composed of Amphiphilic Double-Decker Shaped Polyhedral Oligomeric Silsesquioxanes. J. Colloid Interface Sci. 2011, 355, 106114.

(11) (a) Schoen, B. W.; Lira, C. T.; Lee, A. Separation and Solubility of Cis and Trans Isomers in Nanostructured Double-Decker Silsesquioxanes. J. Chem. Eng. Data 2014, 59, 1483-1493; (b) Schoen, B. W.; Holmes, D.; Lee, A. Identification and Quantification of cis and trans Isomers in Aminophenyl Double-Decker Silsesquioxanes using ${ }^{1} \mathrm{H}-{ }^{29} \mathrm{Si}$ gHMBC NMR. Magn. Reson. Chem. 2013, 51, 490-496; (c) Seurer, B.; Vij, V.; Haddad, T.; Mabry, J. M.; Lee, A. Thermal Transitions and Reaction Kinetics of Polyhedral Silsesquioxane containing Phenylethynylphathalimides. Macromolecules 2010, 43, 9337-9347.

(12) (a) Zhang, X.; Chi, H., Li, T.; Wang, F.; Chin, W-S, Xu, J. Energy Transfer Along a Sequence Controlled Hybrid Polymer. J. Polym. Sci. Part A: Polym. Chem. 2018, 56, 1225-1233; (b) Au-Yeung, H.-L.; Leung, S. Y.-L.; Yam, V. W.-W. Supramolecular assemblies of Dinuclear Alkynylplatinum(II)terpyridine Complexes with Double-Decker Silsesquioxane nano-cores: the Role of Isomerism in Constructing Nano-Structures. Chem. Commun. 2018, 54, 4128-4131; (c) Cao, J.; Fan, H.; Li, B.-G.; Zhu, S. Synthesis and Evaluation of Double-Decker Silsesquioxanes as Modifying Agent for Epoxy Resin. Polymer, 2017, 124, 157-167; Wei, Y., Jiang, Q., Hao, J., Mu, J. Comparative Synthesis and Properties of POSS-based Fluorinated Poly-ether)sulfone Random Terpolymers. RSC Adv. 2017, 7, 3914-3920; (e) Walczak, M.; Januszewski, R.; Majchrzak, M.; Kubicki, M.; Dudziec, B.; Marciniec, B. Unusual cis and trans Architecture of Dihydrofunctional DoubleDecker Shaped Silsesquioxane and Synthesis of its Ethyl Bridged $\pi$ Conjugated Arene Derivatives. New J. Chem. 2017, 41, 3290-3296; (f) Liu N.; Zheng, S. Organic-Inorganic Poly( $N$-vinylpyrrolidone) Copolymers with Double-Decker Silsesquioxane in the Main Chains: Synthesis, Glass Transition and Self-Assembly Behavior. J. Polym. Sci. Part A: Polym. Chem. 2016, 54, 2949-2961; (g) Wang, L.; Zhang, C.; Zheng, S. Organic-Inorganic Poly(hydroxyether of bisphenol A) Copolymers with Double-Decker Silsesquioxane in the Main Chains. $J$. Mater. Chem. 2011, 21, 19344- 19352; (h) Seino, M.; Hayakawa, T.; Ishida, Y.; Kakimoto, M.-A. Hydrosilylation Polymerization of Double-Decker-Shaped Silsesquioxance Having Hydrosilane with Diynes. Macromolecules 2006, 39, 3473-3475.

(13) (a) Żak, P.; Dudziec, B.; Dutkiewicz, M.; Ludwiczak, M.; Marciniec, B.; Nowicki, M. A New Class of Stereoregular Vinylene-Arylene Copolymers with Double-Decker Silsesquioxane in the Main Chain. $J$. Polym. Sci. Part A: Polym. Chem. 2016, 54, 1044-1055; (b) Żak, P.; Majchrzak, M.; Wilkowski, G.; Dudziec, B.; Dutkiewicz, M.; Marciniec, B. Synthesis and Characterization of Functionalized Molecular and Macromolecular Double-Decker Silsesquioxane Systems. RSC $A d v$. 2016, 6, 10054-10063; (c) Liu, N.; Wei, K.; Wang, L.; Zheng, S. Organic-Inorganic Polyimides with Double Decker Silsesquioxane in the Main Chains. Polym. Chem. 2016, 7, 1158-1167; (d) Żak, P.; Dudziec, B.; Kubicki, M.; Mariniec, B. Silylative Coupling versus Metathesis-Efficient Methods for the Synthesis of Difunctionalized Double-Decker Silsesquioxane Derivatives. Chem. Eur. J. 2014, 20, 93879393; (e) Huang, J.; Wang, W.; Gu, J.; Zhang, Q.; Ding, Y.; Xi, K.; Zheng, Y.; Jia, X. New Bead Type and High Symmetrical DiallylPOSS Based Emissive Conjugated Polyfluorene. Polym. 2014, 55, 6696-6707.
(14) (a) Wei, K.; Wang, L.; Zheng, S. Organic-Inorganic Copolymers with Double Decker Silsesquioxane in the Main Chains by Polymerization via Click Chemistry. J. Polym. Sci. Part A: Polym. Chem. 2013, 51, 4221-4232; (b) Ervithayasuporn, V.; Wang, X.; Kawakami, Y. Synthesis and Characterization of Highly Pure Azido-Functionalized Polyhedral Oligomeric Silsesquioxanes (POSS). Chem. Coтmun. 2009, $5130-5132$.

(15) (a) Mitufa, K. Duszczak, J.; Brząkalski, D.; Dudziec, B.; Kubicki, M.; Marciniec, B. Tetra-Functional Double-Decker Silsesquioxanes as Anchors for Reactive Functional Groups and Potential Synthons for Hybrid Materials. Chem. Commun. 2017, 53, 10370-10373; (b) Grzelak, M.; Frąckowiak, D.; Marciniec, B. Vinyl-Functionalized Silsesquioxanes and Germasilsesquioxanes. Eur. J. Inorg. Chem. 2017, 3337-3342.

(16) (a) Sodkhomkhum, R.; Ervithayasuporn, V. Synthesis of Poly(siloxane/Double-Decker Silsesquioxane) via Dehydrocarbonative Condensation Reaction and its Functionalization. Polymer, 2016, 86, 113119. (b) Ervithayasuporn, V.; Sodkhomkhum, R.; Teerawatananond, T.; Phurat, C.; Phinyocheep, P.; Somsook, E.; Osotchan, T. Unprecedented Formation of cis- and trans-Di[(3-chloropropyl)isopropoxysilyl]-Bridged Double-Decker Octaphenylsilsesquioxanes. Eur. J. Inorg. Chem. 2013, 3292-3296.

(17) $\left(\mathrm{Ph}_{8} \mathrm{O}_{8} \mathrm{Si}_{8}\right)(\mathrm{ONa})$ (DDSQ-4ONa) was obtained by a known procedure: Lee, D. W.; Kawakami, Y. Incompletely Condensed Silsesquioxanes: Formation and Reactivity. Polym. J. 2007, 39, 230-238.

(18) For ${ }^{29} \mathrm{Si}$ chemical shifts, see: (a) For 3: Lee, K. (Aminomethyl)pyridine Complexes for the Cobalt-Catalyzed Anti-Markovnikov Hydrosilylation of Alkoxy- or Siloxy(vinyl)silanes with Alkoxy- or Siloxyhydrosilanes. Angew. Chem. Int. Ed. 2017, 56, 3665-3669; (b) For 4: Drazkowski, D. B.; Lee, A.; Haddad, T. S.; Cookson, D. J. Chemical Substituent Effects on Morphological Transitions in Styrene-ButadieneStyrene Triblock Copolymer Grafted with Polyhedral Oligomeric Silsesquioxanes. Macromolecules 2006, 39, 1854-1863. 


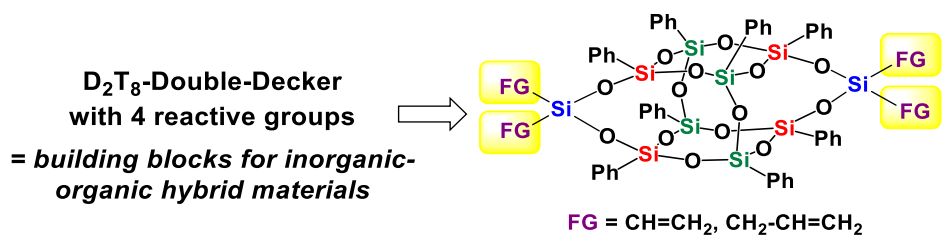

Novel tetravinyl- and tetraallyl-substituted closed double-decker siloxanes (DDSQ) were synthesized and peripheral olefins shown to successfully undergo hydrosilylation quantitatively. Such tetra-functionalizable DDSQ thus constitute promising building blocks for more complex inorganic-organic hybrid materials. 